\section{Macrophage ferroportin is essential for stromal cell proliferation in wound healing}

\author{
Stefania Recalcati, ${ }^{1 *}$ Elena Gammella, ${ }^{1 *}$ Paolo Buratti ${ }^{1}$ Andrea Doni, ${ }^{2}$ \\ Achille Anselmo, ${ }^{2}$ Massimo Locati ${ }^{2,3}$ and Gaetano Cairo ${ }^{1}$
}

${ }^{1}$ Department of Biomedical Sciences for Health, University of Milan; ${ }^{2}$ Humanitas Clinical and Research Center, Rozzano and ${ }^{3}$ Department of Medical Biotechnologies and Translational Medicine, University of Milan, Italy

\# SR and EG contributed equally to this work

\author{
Haematologica 2019 \\ Volume 104(1):47-58
}

\title{
ABSTRACT
}

$\tau$ ron recycling by macrophages is essential for erythropoiesis, but may also be relevant for iron redistribution to neighboring cells at the local tissue level. Using mice with iron retention in macrophages due to targeted inactivation of the iron exporter ferroportin, we investigated the role of macrophage iron release in hair follicle cycling and wound healing, a complex process leading to major clinical problems, if impaired. Genetic deletion of ferroportin in macrophages resulted in iron deficiency and decreased proliferation in epithelial cells, which consequently impaired hair follicle growth and caused transient alopecia. Hair loss was not related to systemic iron deficiency or anemia, thus indicating the necessity of local iron release from macrophages. Inactivation of macrophage ferroportin also led to delayed skin wound healing with defective granulation tissue formation and diminished fibroplasia. Iron retention in macrophages had no impact on the inflammatory processes accompanying wound healing, but affected stromal cell proliferation, blood and lymphatic vessel formation, and fibrogenesis. Our findings reveal that iron/ferroportin plays a largely underestimated role in macrophage trophic function in skin homeostasis and repair.

\section{Introduction}

Tissue resident macrophages play an important role both in tissue homeostasis, by supporting neighboring parenchymal cells with trophic signals and nutrients, and in tissue repair following injury. ${ }^{1-4}$ In the skin context, macrophages are critical regulators of hair follicle growth ${ }^{5}$ and cutaneous wound healing, two events with many similarities. ${ }^{6}$ Indeed, perifollicular macrophages prompt the entry of hair follicle stem cells into the anagen phase of growth, ${ }^{7}$ while selective ablation of macrophages impairs the wound healing response. ${ }^{8}$ Although wound macrophages display a mixed phenotypic and functional profile, the initial phase of an injury is characterized by the prevalence of pro-inflammatory, classically activated M1 macrophages, which are associated with the production of oxygen radicals and pro-inflammatory cytokines. Conversely, at later stages during resolution of inflammation and tissue repair, alternatively polarized M2 macrophages oriented to tissue repair and remodeling, predominate. ${ }^{1,9}$ This M1 to M2 switch is required for normal healing. ${ }^{2}$

Macrophages are also at the cross-road of iron traffic. ${ }^{10,11}$ Iron-recycling macrophages provide iron for erythropoiesis by clearing senescent erythrocytes. ${ }^{12}$ Conversely, iron sequestration by pro-inflammatory macrophages is a wellknown mechanism of efficient bacteriostasis in host defense. ${ }^{13}$ In line with their different functions in homeostatic and inflammatory conditions, polarized macrophages show considerable differences in their transcriptional profiles, ${ }^{14}$ including a distinct regulation of genes related to iron metabolism. ${ }^{11,15}$ Iron retention by M1 macrophages correlates with high expression of the iron storage protein ferritin. Conversely, M2 macrophages display increased heme uptake and production of anti-inflammatory mediators via heme oxygenase-dependent heme

\section{Correspondence: \\ gaetano.cairo@unimi.it or massimo.locati@humanitasresearch.it or massimo.locati@unimi.it \\ Received: May 14, 2018. Accepted: August 14, 2018. \\ Pre-published: August 16, 2018. \\ doi:10.3324/haematol.2018.197517}

Check the online version for the most updated information on this article, online supplements, and information on authorship \& disclosures: www.haematologica.org/content/104/1/47

(C)2019 Ferrata Storti Foundation

Material published in Haematologica is covered by copyright. All rights are reserved to the Ferrata Storti Foundation. Use of published material is allowed under the following terms and conditions:

https://creativecommons.org/licenses/by-nc/4.0/legalcode. Copies of published material are allowed for personal or internal use. Sharing published material for non-commercial purposes is subject to the following conditions: https://creativecommons.org//licenses/by-nc/4.0/legalcode, sect. 3. Reproducing and sharing published material for commercial purposes is not allowed without permission in writing from the publisher. 
catabolism, as well as high expression of the iron exporter ferroportin (FPN). ${ }^{16}$

A tight control of iron metabolism is needed for appropriate tissue homeostasis and healing. Excess iron, both in macrophages and in the extracellular milieu, has a deleterious effect on tissue repair, ${ }^{17}$ and heme iron has pro-oxidant and pro-inflammatory properties, so that its clearance and degradation by $\mathrm{M} 2$ macrophages contributes to resolution. ${ }^{18}$ However, it is also conceivable that increased iron retention in macrophages leads to lower iron availability for neighboring cells, thus compromising the trophic role of macrophages. In fact, given the necessity of iron for many essential biological functions, including cell replication, ${ }^{19,20}$ defective iron release can jeopardize iron-dependent functions essential for cutaneous homeostasis and efficient tissue restoration. Decreased iron availability could impair the growth of fibroblasts, as well as epithelial and endothelial cells during new tissue formation. Moreover, the hydroxylases necessary for efficient collagen assembly during the repair phase are irondependent enzymes. ${ }^{21}$

In this study, we investigated the role of macrophage iron metabolism in tissue homeostasis and repair exploiting a mouse line with iron retention in macrophages caused by targeted FPN inactivation in cells of the myeloid lineage, thus avoiding artefactual systemic iron overload and other confounding elements, such as increased local iron accumulation in other cell types. Using the skin as a model tissue, we show that macrophage-dependent FPN-mediated iron release is required for hair growth in homeostatic conditions and for efficient wound healing, a process which is essential for survival and also clinically relevant, as nonhealing wounds are a major clinical problem associated with various human diseases. ${ }^{22,23}$

\section{Methods}

\section{Animals}

The crossing of mice carrying a floxed Fpn allele $\left(\mathrm{Fpn}^{\mathrm{f} / \mathrm{f}}\right),{ }^{24}$ provided by Dr Nancy Andrews, with mice expressing Cre under the control of the LysM promoter in the C57BL/6J background ${ }^{25}$ in order to generate mice with specific FPN-macrophage inacti-

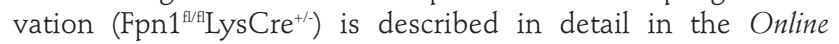
Supplementary Material.

Procedures involving animals handling and care conformed with protocols approved by the Humanitas Clinical and Research Center in compliance with national (DL 116, GU suppl. 40, 18-2-1992; DL 26, GU 4-3-2014) and international law and policies (EEC Council Directive 2010/63/EU, OJ L 276/33, 22-09-2010; National Institutes of Health Guide for the Care and Use of Laboratory Animals, US National Research Council, 2011). The study was approved by the Italian Ministry of Health. All efforts were made to minimize the number of animals used and their suffering.

\section{Statistical analysis}

Results are expressed as the mean \pm standard error of mean. Statistical significance between two groups was assessed by an unpaired two-tailed Mann-Whitney test or Student $t$ test with Prism software (GraphPad). For comparison of more than two groups, data were analyzed using one-way analysis of variance (ANOVA).

Full details of the Methods are available in the Online Supplementary Material.

\section{Results}

\section{Ferroportin deletion in macrophages causes hair follicle alterations and alopecia}

To generate mice that lack FPN in macrophages, we crossed $\mathrm{Fpn}^{\mathrm{f} / \mathrm{fl}}$ mice $^{24}$ with LysMCre mice ${ }^{25}$ to create myeloid cell-specific FPN knockout mice. The phenotypic characterization of these Fpn1 ${ }^{\mathrm{E} / \mathrm{I}} \mathrm{LysCre} \mathrm{Cr}^{+/}$mice is described in the Online Supplementary Material and illustrated in Online Supplementary Figure S1. FPN deletion in macrophages resulted in a significant decrease of hematologic parameters, such as hemoglobin level and hematocrit (Figure 1A,B), and red blood cell count, mean corpuscular volume and mean cell hemoglobin (Online Supplementary Table S1), at weaning (3 weeks after birth). Thereafter, both parameters rapidly returned to normal levels and remained almost unaltered until 18 weeks. In line with the mild anemia observed in 2-month old 129/SvEvTac mice lacking macrophage FPN, ${ }^{26}$ in weaned Fpn $1^{\mathrm{E} / \mathrm{I}} \mathrm{LysCre}^{+/}$mice hemoglobin levels and hematocrit were lower than in

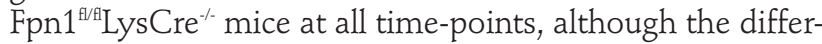
ence never reached statistical significance (Figure 1A,B). Serum iron levels and transferrin saturation showed a tendency to decrease with age, but were never statistically different between Fpn1 ${ }^{\mathrm{A} / \mathrm{I}} \mathrm{LysCre}^{+/-}$mice and their control Fpn $1^{\mathrm{t} / \mathrm{I}}$ LysCre $\mathrm{e}^{-/}$littermates. The hepatic expression of hepcidin (HAMP), which regulates systemic iron homeostasis by inhibiting $\mathrm{FPN},{ }^{20}$ showed age-related variations but was not different between Fpn $1^{\mathrm{fl} / \mathrm{I}}$ LysCre ${ }^{+/-}$mice and their control littermates. Similarly, we did not detect significant differences in skin HAMP mRNA levels, which were much lower than in the liver (Figure 1B), while hepcidin levels in skin lysates were undetectable. Accordingly, the expression of Fam $132 \mathrm{~b}$ mRNA encoding for erythroferrone, the erythroid regulator of hepcidin, ${ }^{27}$ was unchanged in both spleen and bone marrow (Figure $1 \mathrm{~B}$ and Online Supplementary Figure S2). Fpn1 $1^{\mathrm{A} / \mathrm{I}} \mathrm{LysCre}^{+/}$mice showed diffuse alopecia with sparing of the head in $100 \%$ of both male and female mice until the fourth week of age (Figure 1A,C). Histological analysis in 3-week old mice showed no differences between the two genotypes in any organ evaluated, with the exception of the increased iron accumulation in spleen and liver macrophages (Online Supplementary Figure S1) and a moderate/severe and diffuse/multifocal to coalescing dilatation of hair follicles, which contained remnants of hair shafts and keratin, and slight acanthosis of the superficial epidermis (Figure 1C). Alopecia gradually disappeared and hair re-growth was evident starting 2 weeks after weaning (Figure 1A), but minor skin alterations were still detectable in adult Fpn $1^{\mathrm{f} / \mathrm{I}} \mathrm{LysC} \mathrm{Cr}^{+/}$mice, which had a reduced number of hair follicles, multifocal areas of hair shaft rarefaction and a thin hypodermis with an apparent increase of adipose tissue (Figure 1D). Taken together, these results indicate that targeted FPN deletion in macrophages results in severe alterations of the hair follicle and transient alopecia.

\section{Alopecia is not related to systemic iron deficiency}

In Fpn $1^{1 / A}$ LysCre ${ }^{+/-}$mice hair regrowth was not complete until 3 weeks after weaning, while hemoglobin levels and hematocrit had already returned to normal after 1 week (Figure 1A) and at all time-points there was no difference in serum iron availability between Fpn ${ }^{\mathrm{f} / \mathrm{A}} \mathrm{Lys} \mathrm{Cre}^{+/-}$and control littermates. This suggested that alopecia in Fpn1 $1^{\mathrm{f} / \mathrm{I}} \mathrm{LysCre}^{+/}$ mice was not a local reflection of systemic iron deficiency 
A
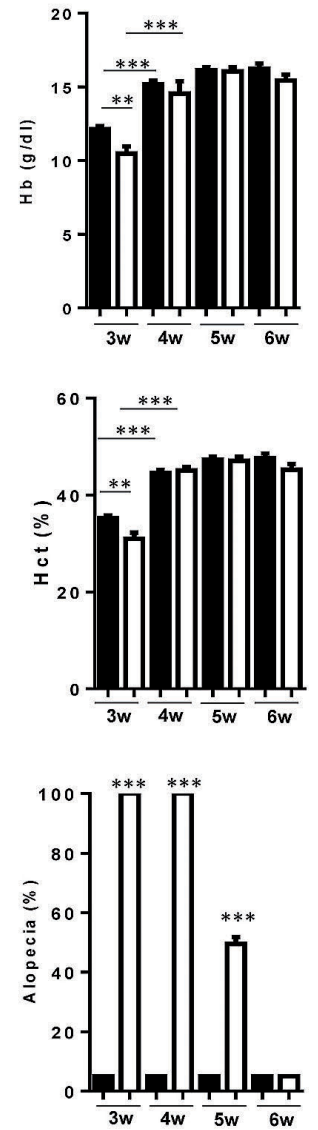

B
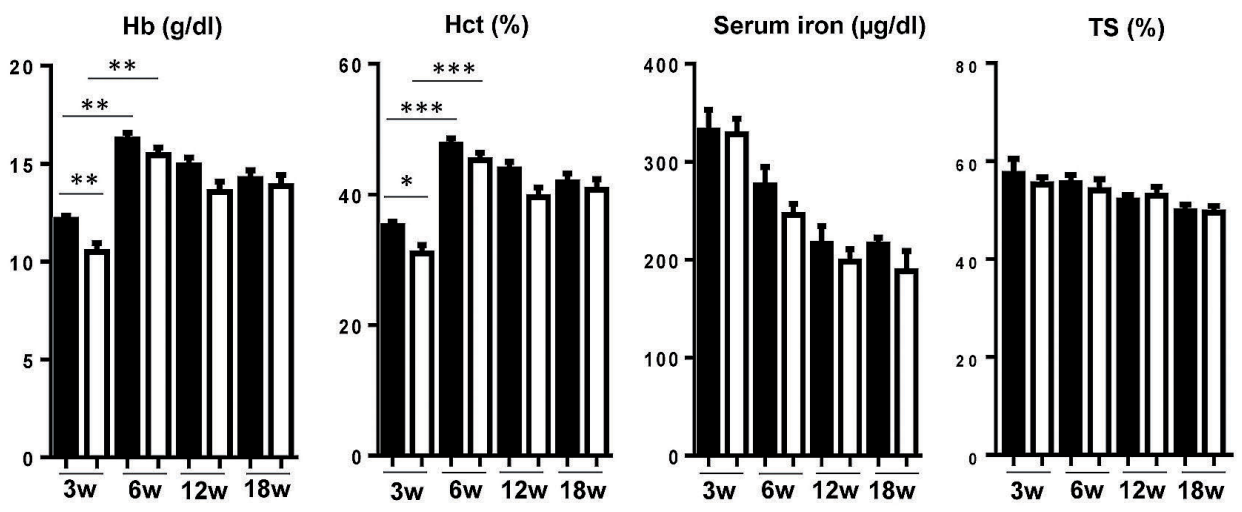

HAMP mRNA (HAMP/18S)
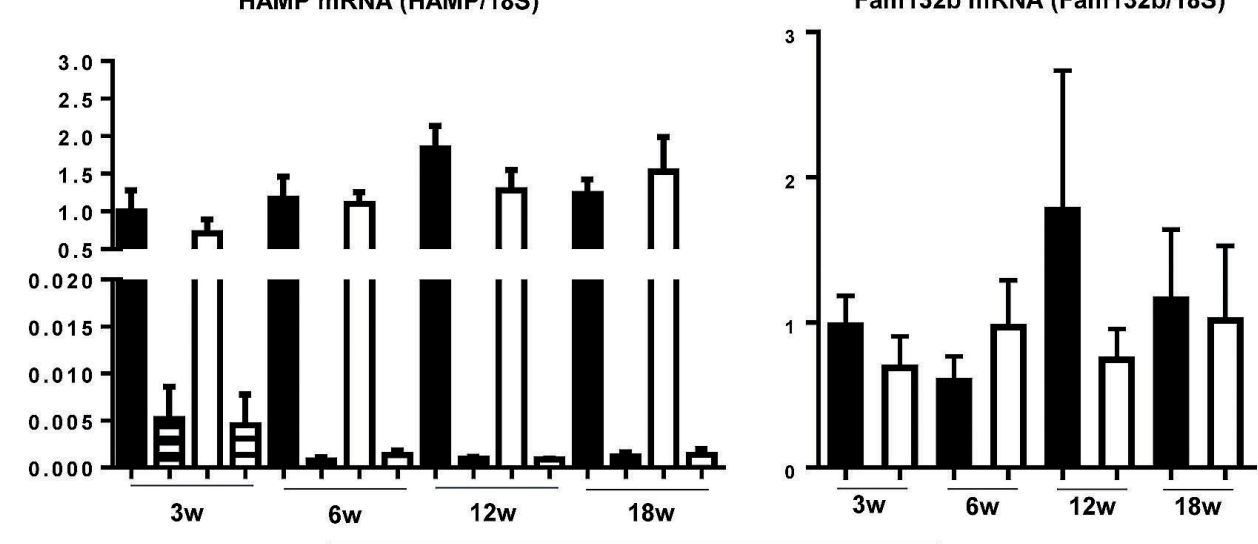

Fpn1 ${ }^{\text {fl/fILysCre }}{ }^{-/-} \square$ Fpn1 $^{\text {fl/fl'LysCre }}{ }^{+/-}$

C
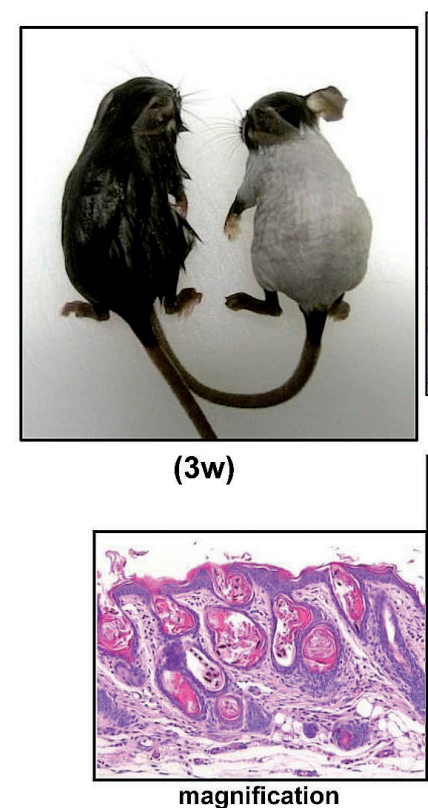

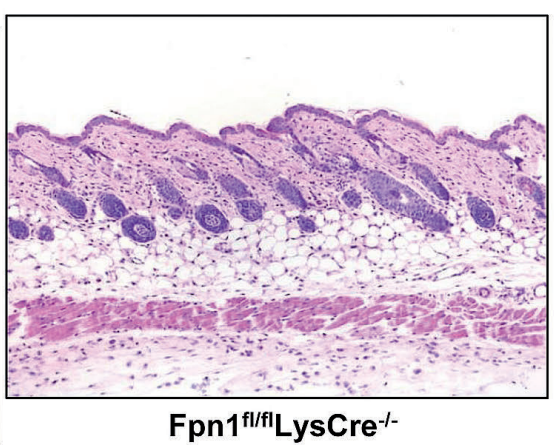

Fpn1 ${ }^{\text {fl/flLysCre }}{ }^{-/}$

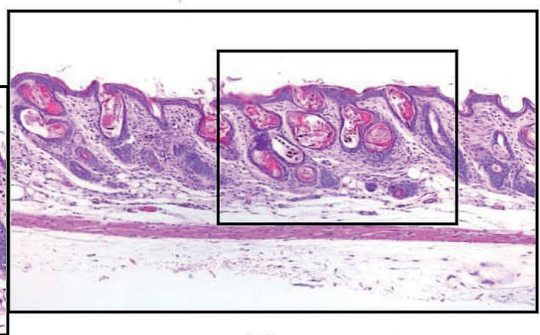

Fpn1 ${ }^{\text {fl/flLysCre }}{ }^{+/-}$
D

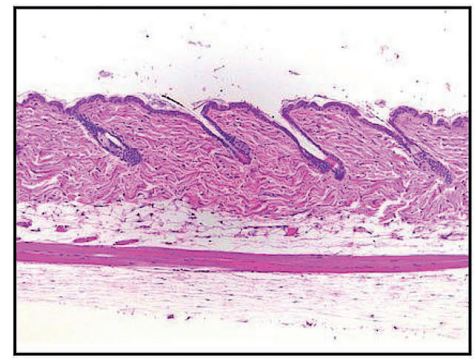

Fpn $1^{\text {fl/fl }}$ LysCre $^{-/-}(12 w)$

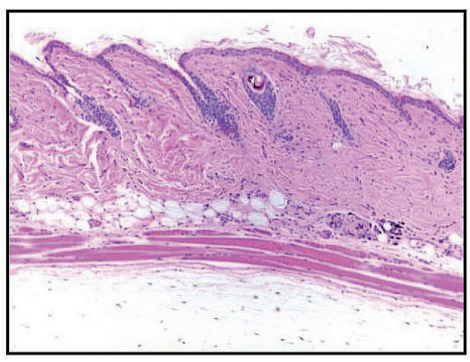

Fpn1 ${ }^{\text {fl/fl LysCre }}{ }^{+/-}(12 w)$

Figure 1. Transient alopecia and anemia are present in Fpn1 $1^{\mathrm{ft} / \mathrm{L}} \mathrm{LysCre}{ }^{+/}$mice. (A) Hemoglobin $(\mathrm{Hb})$ levels and hematocrit $(\mathrm{Hct})$ in 3- to 6 -week (w) old mice (mean \pm SEM of 50 mice for each group; $* * * P<0.0001, * * P<0.001$ ). The histogram at the bottom shows the percentage alopecia at different time-points (mean \pm SEM of

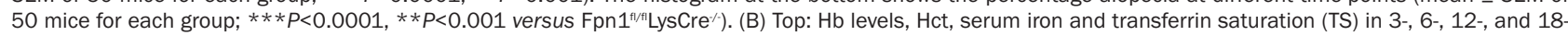
week old mice (mean \pm SEM of 50 mice for each group; $* * * P<0.0001, * * P<0.001, * P<0.01$ ). Bottom: hepcidin (HAMP) expression in the liver (solid bars) and skin (striped bars) and spleen erythroferrone (Fam132b) mRNA levels of 3-, 6-, 12-, and 18-week old mice. mRNA levels were measured by quantitative real time polymerase chain reaction and normalized to the housekeeping gene $18 \mathrm{~S}$ RNA. Data are presented as mean \pm SEM of 10 mice for each group. (C) Representative appearance of 3-week old Fpn1 $1^{\mathrm{f} / \mathrm{t}} \mathrm{LysCre} \%$ (left) and Fpn1 $1^{\mathrm{t} / \mathrm{L}} \mathrm{LysCre} \mathrm{Cr}^{+/}$(right) mice and representative histology (dorsal area) of the same mice. Magnification 10X, in the inset 20X. (D) Representative histology of the skin (dorsal area) of adult (12-week old) mice. Tissue sections were stained with hematoxylin and eosin. Magnification: 10X. 
but a consequence of iron sequestration in skin macrophages, ultimately resulting in impaired hair follicle growth. To further assess this issue, we analyzed hematologic parameters and alopecia after exposure to low iron diet according to the protocol outlined in Figure 2A. Until week 5, both Fpn1 $1^{\mathrm{A} / \mathrm{A}} \mathrm{LysCre}^{+/-}$and control littermates were anemic, and hemoglobin levels and other hematologic parameters were always slightly and not significantly lower in animals lacking macrophage FPN (Figure 2B,C, Online Supplementary Table S1). Serum iron levels and transferrin saturation were lower in 3-week old Fpn $1^{\mathrm{A} / \mathrm{I}} \mathrm{LysCre}^{+/}$ mice than in control littermates, although not statistically significantly so, but returned to normal levels at 6 weeks without differences between the two strains (Figure 2C). Liver hepcidin expression was repressed by the iron-deficient diet, but was not different between Fpn $1^{\mathrm{E} / \mathrm{I}} \mathrm{LysCre}^{+/}$ mice and their control littermates (Figure 2C). HAMP mRNA levels in the skin were below the threshold of detection. A significant increase in erythroferrone expression was found in Fpn1 ${ }^{\mathrm{E} / \mathrm{A}} \mathrm{LysCre}^{+/}$pups at 3 weeks (Figure 2C and Online Supplementary Figure S2), which is indicative of higher erythropoietic activity. After the introduction of the normal diet, both hepcidin and erythroferrone expression returned to normal levels (Figure 2C and Online Supplementary Figure S2). Mice with loss of macrophage FPN were grossly affected by diffuse alopecia of the trunk throughout the period of exposure to the low iron diet, whereas Fpn $1^{\text {A/AII LysCre }}{ }^{-/}$mice, despite low serum iron availability, did not develop alopecia (Figure 2B). Remarkably, alopecia did not appear in Fpn $1^{\mathrm{A} / \mathrm{L}} \mathrm{LysCre}^{-/}$mice even after exposure to the iron-deficient diet for 11 weeks. In $\mathrm{Fpn}^{\mathrm{E} / \mathrm{I}} \mathrm{LysCre} \mathrm{Cr}^{+/}$mice, after reintroduction of a normal diet, hemoglobin and serum iron returned to normal levels 2 weeks before the restoration of normally haired skin (Figure 2B,C), thus indicating that alopecia and hypoferremia/anemia are not associated. Histological analysis showed that in Fpn1 $1^{\mathrm{E} / \mathrm{L}} \mathrm{LysCre} \mathrm{Cr}^{+/}$mice challenged with the low iron diet alopecia was associated with severe follicular keratosis with intraluminal accumulation of keratin and distorted hair shafts and subsequent dilation of the hair follicles. Conversely, no relevant histopathological changes were found in the haired skin of the Fpn1 ${ }^{\mathrm{E} / \mathrm{I}} \mathrm{LysCre}^{-/}$mice maintained in the same dietary conditions (Figure 2D). Both in Fpn1 $1^{\mathrm{A} / \mathrm{A}} \mathrm{LysCre}^{+/-}$and Fpn1 $1^{\mathrm{E} / \mathrm{A}} \mathrm{LysCre}^{-/}$mice maintained under iron deprivation conditions for 5 weeks and subsequently fed a normal diet for 2 weeks, skin histology showed that hair follicles were in the anagen stage, but in Fpn $1^{\mathrm{t} / \mathrm{L}} \mathrm{LysCre}^{+/-}$mice hair shafts did not exit the follicular ostia and follicular keratosis/dilation, increased epidermal hyperplasia and dermal inflammation were observed (Figure 2E).

\section{Ferroportin deletion in macrophages leads to epithelial iron deficiency and decreased proliferation in cutaneous hair follicles}

Since we showed that iron released by macrophages via FPN supports in vitro cell proliferation, ${ }^{15}$ an important role for FPN in skin macrophages could be to mediate the release of sufficient iron in the microenvironment for cell multiplication. Indeed, confocal microscopy revealed a significantly lower expression of the proliferation marker Ki67 in the epithelial cells of the hair bulbs of 3-week old Fpn $1^{\mathrm{t} / \mathrm{L}}$ LysCre ${ }^{+/}$mice (Figure 3 ). Conversely, in the same cells we found a strong increase of transferrin receptor (TfR1) expression, which is indicative of cellular iron dep- rivation (Figure 3). Notably, F4/80+ macrophages, which are abundant in the skin stroma but with no differences in number between Fpn1 $1^{\mathrm{f} / \mathrm{L}} \mathrm{LysCre}{ }^{+/}$and Fpn1 $1^{\mathrm{E} / \mathrm{I}} \mathrm{LysCre}^{-/-}$mice (Figure 3), expressed lower levels of both Ki67 and TfR1 but had an increased content of both the $\mathrm{L}$ and $\mathrm{H}$ subunits of the iron storage protein ferritin (Figure 3 and Online Supplementary Figure S3) as compared to epithelial cells. Qualitative analysis also showed that in Fpn ${ }^{\mathrm{A} / \mathrm{L} / \mathrm{LysCre}}$ mice ferritin is detectable only in epithelial cells (Online Supplementary Figure S3), whereas in Fpn1 ${ }^{\text {I//il }}$ LysCre $^{+/}$mice ferritin expression is particularly strong in $\mathrm{F} 4 / 80^{+}$ macrophages. These results suggest that iron retention in resident macrophages, by starving neighboring hair follicle cells of iron and hence inhibiting their proliferation, has detrimental effects on tissue homeostasis.

\section{Ferroportin deletion in macrophages compromises wound healing}

Resident macrophages support parenchymal cells with trophic signals, particularly under conditions characterized by increased cell proliferation, such as during tissue repair following injury. ${ }^{2}$ To test the role of macrophagederived iron in this context, we investigated the wound healing process after incisional skin damage during the entire time course of repair, i.e. the early-inflammatory [2 days post injury (dpi)], middle-proliferative (7 dpi), and late-remodeling phases (12 dpi). We first investigated FPN expression in FACS-sorted macrophages from wounds; in $\mathrm{Fpn}^{\mathrm{E} / \mathrm{l} / \mathrm{I} L y s \mathrm{Cre}}{ }^{-/}$mice FPN mRNA levels progressively increased during repair (Figure 4A), suggesting a predominant role of FPN in the late phases, whereas, as expected, FPN mRNA was always barely detectable in Fpn $^{\text {fl/AlitysCre }}{ }^{+/}$mice. The analysis of other iron-related genes showed a rise in the expression of TfR1, which mediates iron uptake, and a decrease of ferritin $\mathrm{H}$ subunit during the middle-late phase of repair in macrophages of Fpn $1^{\mathrm{E} / \mathrm{A}}$ LysCre ${ }^{-/ /}$mice, but not Fpn1 ${ }^{\mathrm{E} / \mathrm{A}} \mathrm{LysCre}^{+/}$mice, which is evidence of iron deposition in these cells (Figure 4A). Accordingly, histological analysis showed iron accumulation in wound macrophages of Fpn ${ }^{\mathrm{E} / \mathrm{H}} \mathrm{LysCre}^{+/}$mice (Figure 4B). Hepcidin-dependent FPN modulation should not play a role in wound healing, as no difference was seen in liver HAMP expression between Fpn1 $1^{\mathrm{f} / \mathrm{l} / \mathrm{Lys} \mathrm{Cre}^{-/}}$and $\mathrm{Fpn}^{\mathrm{f} / \mathrm{fl}} \mathrm{LysCre}^{+/-}$mice during wound repair (Online Supplementary Figure S4A) and HAMP expression in FACSsorted macrophages was undetectable. Hepcidin levels in the wound lysate, which were much lower than in serum, were not different between Fpn1 ${ }^{\mathrm{A} / \mathrm{I}} \mathrm{LysCre}^{-/}$and Fpn1 $1^{\mathrm{f} / \mathrm{A}} \mathrm{LysCre}^{+/-}$mice (Online Supplementary Figure S4B). Macroscopic analysis of wound size showed that the process of closure was considerably delayed in Fpn $1^{\mathrm{f} / \mathrm{H}}$ LysCre ${ }^{+/-}$mice than in control littermates, with significantly wider lesions at all time points and a lag of 3-5 days at 3 dpi through 12 dpi (Figure 4C). Histological analysis performed according to the criteria described in Online Supplementary Table S2 supported this observation, as Fpn $^{\mathrm{E} / \mathrm{H} / \mathrm{LysCre}}{ }^{+/-}$mice displayed a more prolonged inflammatory response and delayed granulation tissue formation, associated with diminished fibroplasia, whereas mononuclear cells and granulocytes were unchanged (Figure 4D).

\section{Ferroportin deletion in macrophages has no impact on leukocyte recruitment and activation in the wound}

Given the role of leukocytes in tissue repair, ${ }^{23}$ we evaluated leukocyte recruitment in our experimental setting. 
A

Time course (pups)

W (birth)

$3 w$ (weaning) $5 w \quad 6 w$

$12 w$

(dams)t

diet

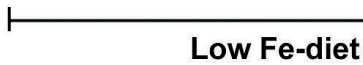

Normal diet

B
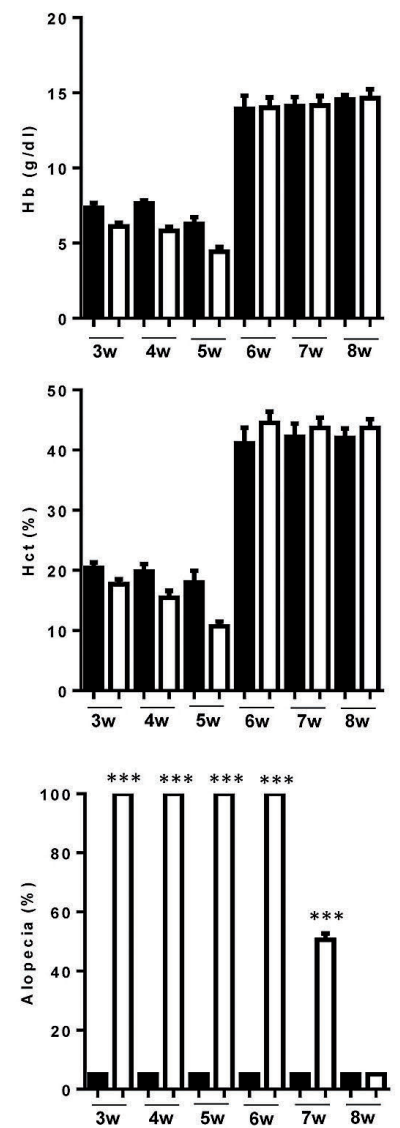

D

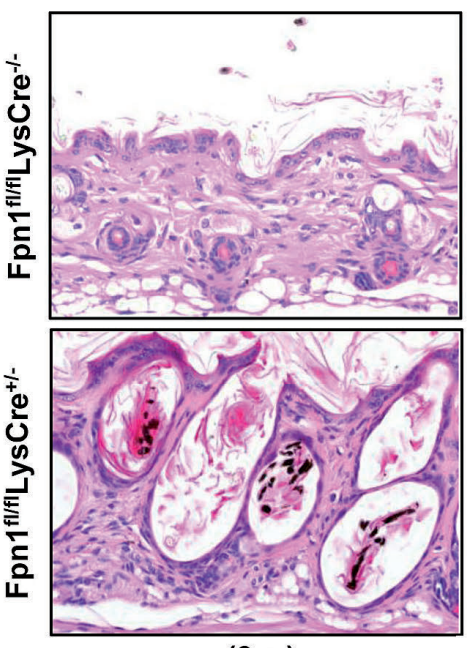

C $\mathrm{Hb}(\mathrm{g} / \mathrm{dl})$

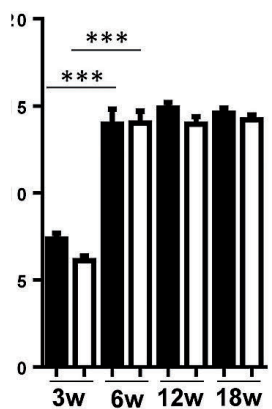

Het (\%)

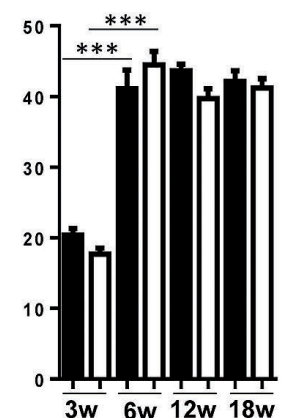

Serum iron $(\mu g / d l)$

TS (\%)
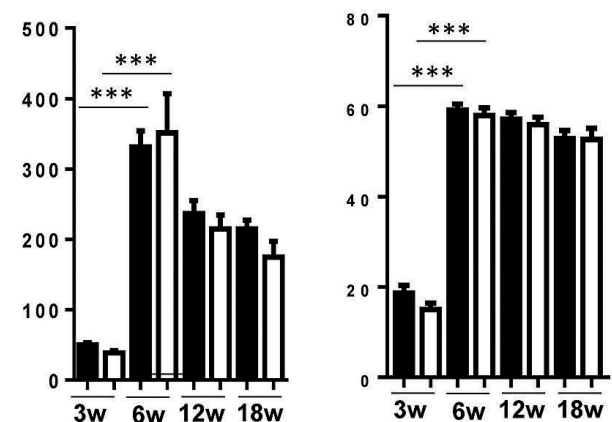
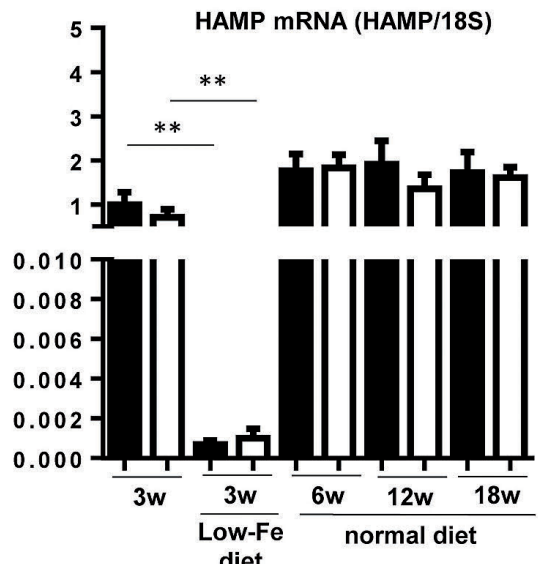

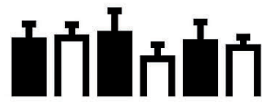

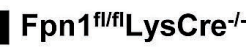
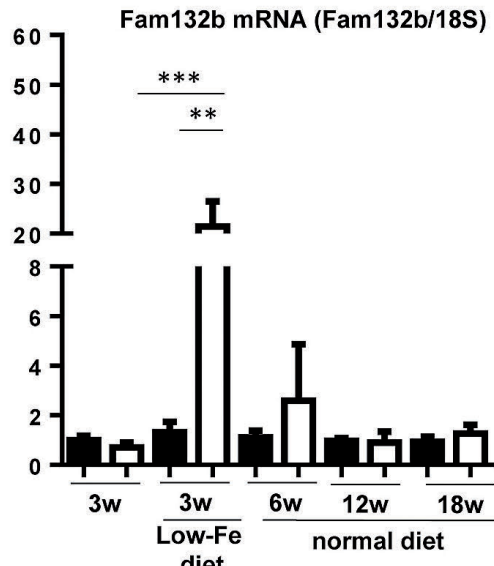

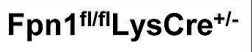
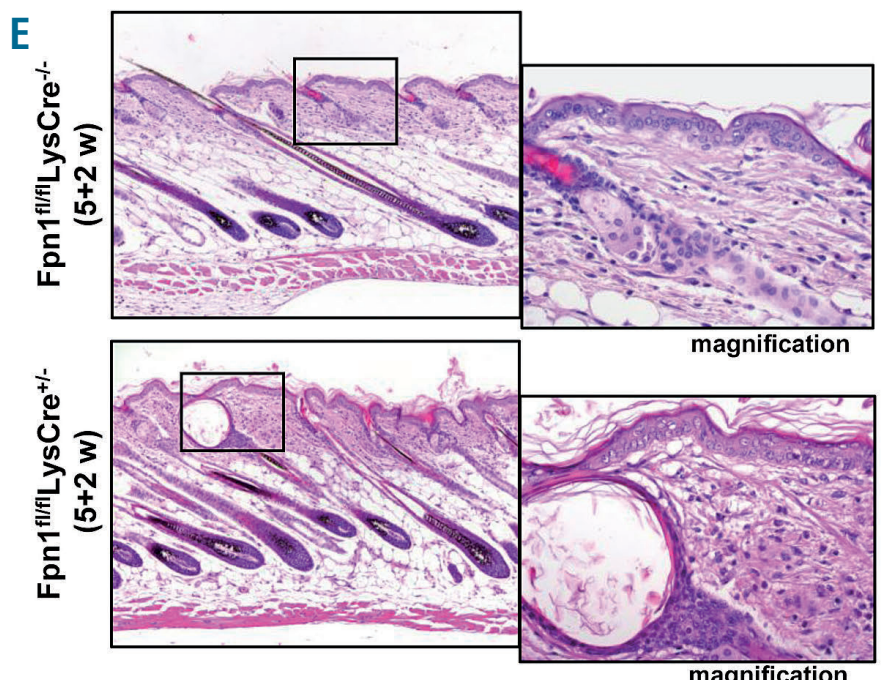

Figure 2. Alopecia in Fpn1 $1^{\mathrm{t} / \mathrm{L}} \mathrm{LysCre}{ }^{+/}$mice is not related to iron deficiency/anemia. (A) Schematic overview of the feeding protocol: pups were fed by dams kept on an iron-deficient diet for 3 weeks until weaning and then maintained on a low iron diet for another 2 weeks followed by a normal diet. (B) Hemoglobin (Hb) levels and hematocrit (Hct) in 3- to 8-week old mice (mean \pm SEM of 10 mice for each group). The histogram at the bottom shows the degree of alopecia at different time-points. $* * * P<0.0001$ versus Fpn1 ${ }^{\mathrm{t} / \mathrm{f}} \mathrm{LysCre} \%$. (C) Top: Hb levels, Hct, serum iron and transferrin saturation (TS) in 3- to 18-week old mice (mean $\pm \mathrm{SEM}$ of 10 mice for each group; $* * * P<0.0001$ ). Bottom: hepcidin (HAMP) and erythroferrone (Fam132b) mRNA levels in the liver and spleen, respectively, of 3- to 18-week old mice. Expression in 3week old mice fed the normal diet is shown in comparison. mRNA levels were measured by quantitative real-time polymerase chain reaction and normalized to the housekeeping gene $18 \mathrm{~S}$ RNA. Data are presented as mean \pm SEM of 10 mice for each group; $* * * P<0.0001, * * P<0.001$. (D) Representative histology of the skin (dorsal area)

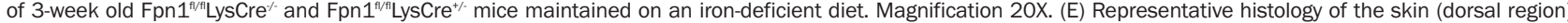
after 5 weeks of an iron deficient diet plus 2 weeks of a normal diet. Tissue sections were stained with hematoxylin and eosin. Magnification: $10 x ; 20 X$ in the insets. 
Neutrophils (Ly6G $\mathrm{G}^{+}$cells) and eosinophils (CCR3 ${ }^{+}$cells) were abundant at 2 and $7 \mathrm{dpi}$ and decreased thereafter, whereas an inverse trend was evident for $\mathrm{T}$ cells $\left(\mathrm{CD}^{+}\right.$ cells) and macrophages (F4/80+ cells), which increased at 12 dpi (Figure 5A). The accumulation kinetics of these cells, which are typical of skin wound healing, ${ }^{22}$ were not affect- ed by the presence or absence of FPN in macrophages.

Macrophages with different functional orientations have specific roles in the overlapping phases of wound repair. ${ }^{1,9}$ As iron accumulation in macrophages might favor the expression of inflammatory mediators. we evaluated the levels of inflammatory cytokines in

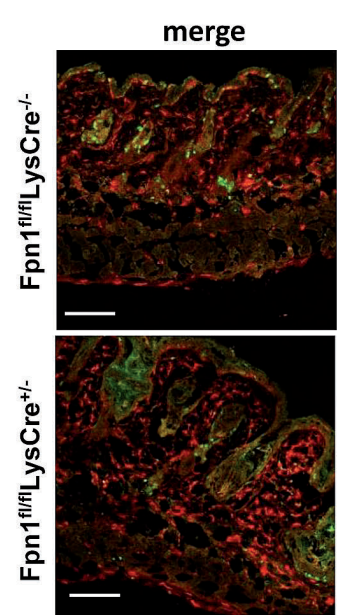

merge
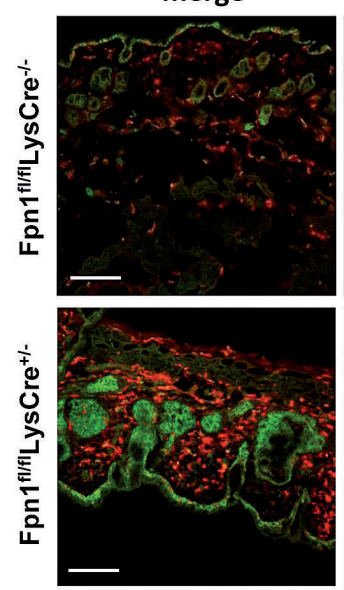

merge

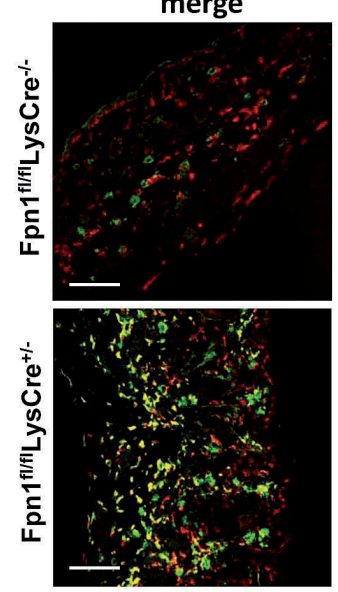

Ki67

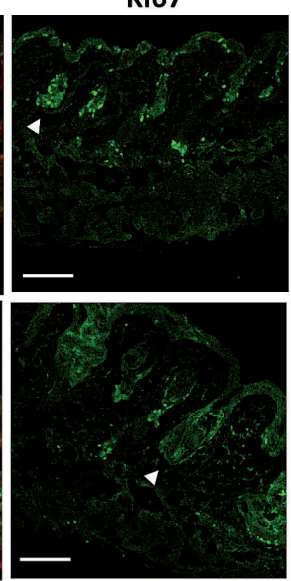

TfR1
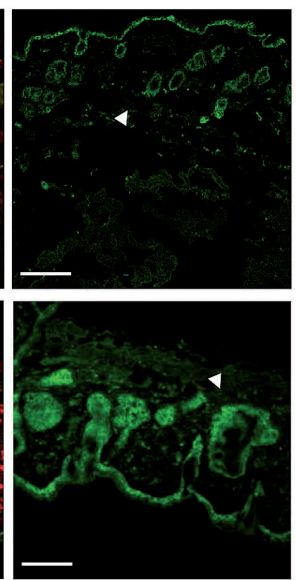

FtL

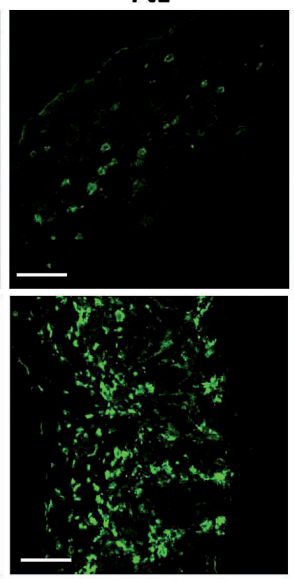

F4/80

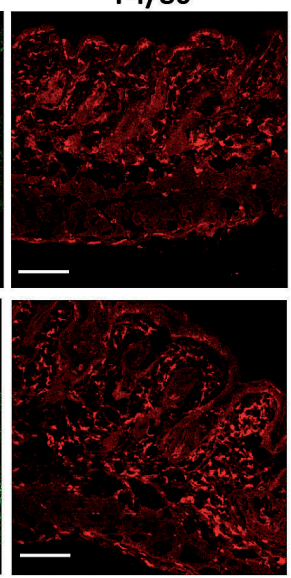

F4/80

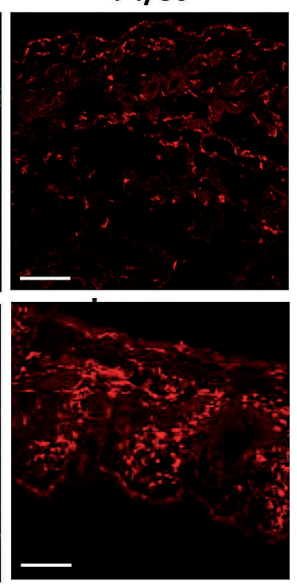

$F 4 / 80$

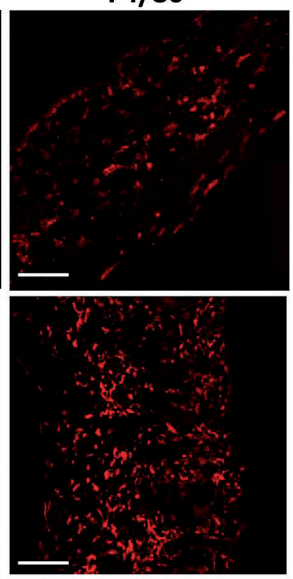

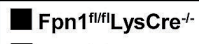

$\square$ Fpn 1 ${ }^{\mathrm{fl} / \mathrm{L}} \mathrm{Lys} \mathrm{Lre}^{+{ }^{+/}}$
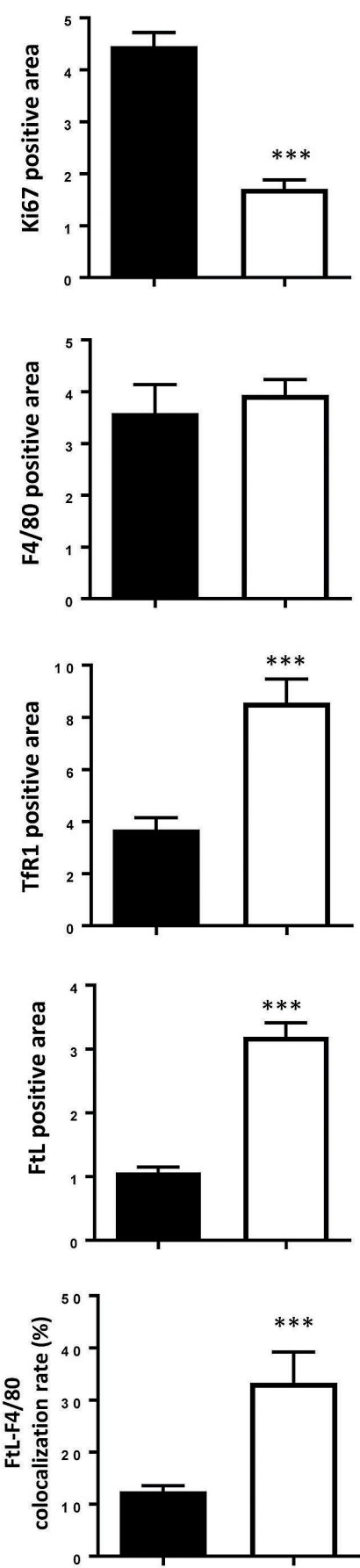

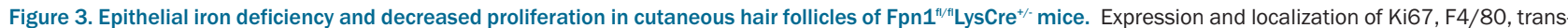

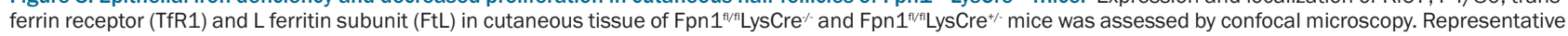
confocal microscopy images for merged signals, Ki67, TfR1, F4/80 and FtL are shown. Quantification of confocal images (5-9 fields of vision/mouse, 3 mice/group) is also reported. $* * * P<0.0001$ versus Fpn1 ${ }^{\sharp / / t}$ LysCre $\%$. Arrowheads indicate hair bulbs. Bars: $100 \mu \mathrm{m}$. Magnification: 40X. 
A

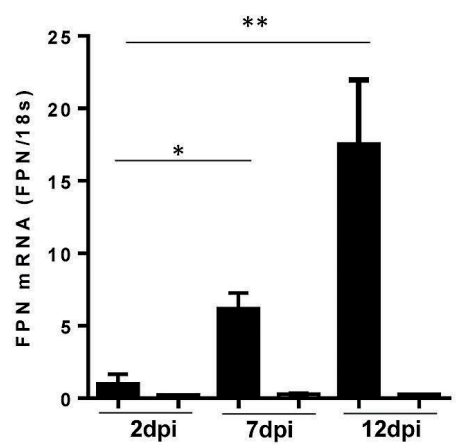

B

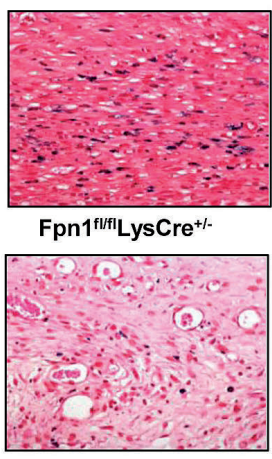

Fpn1 $1^{\text {flflil } L y s C r e}{ }^{-1-}$

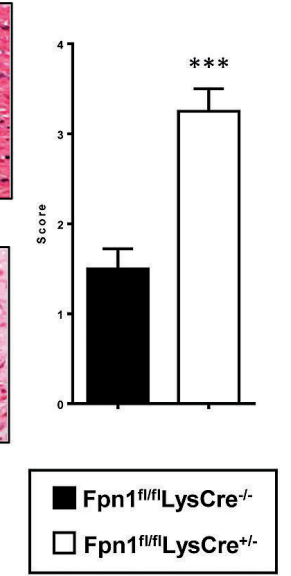

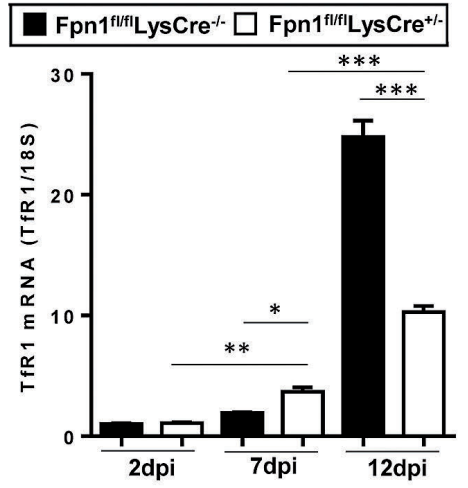

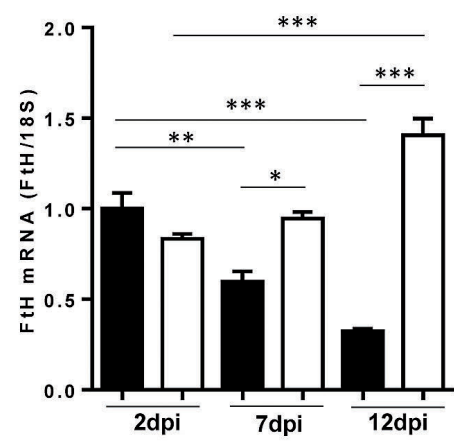

C 120

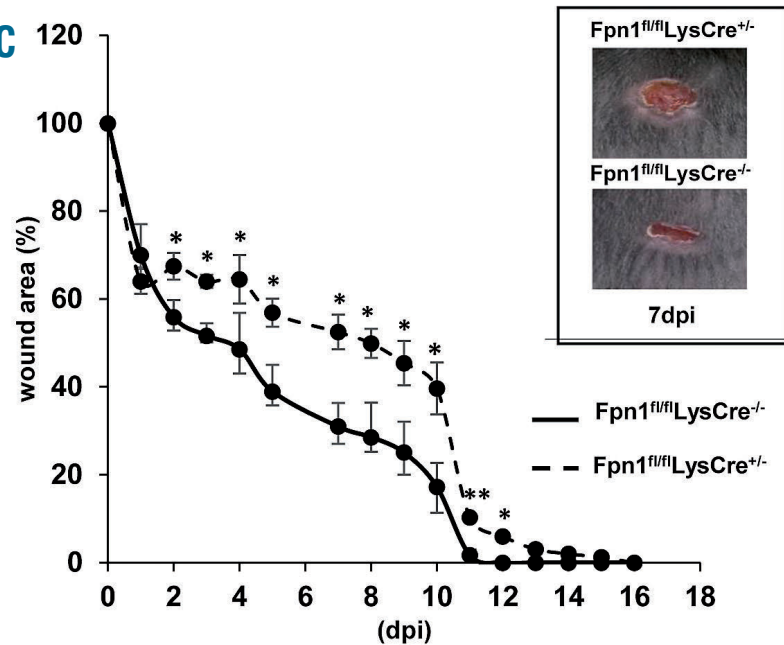

D

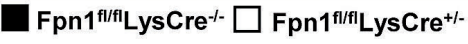
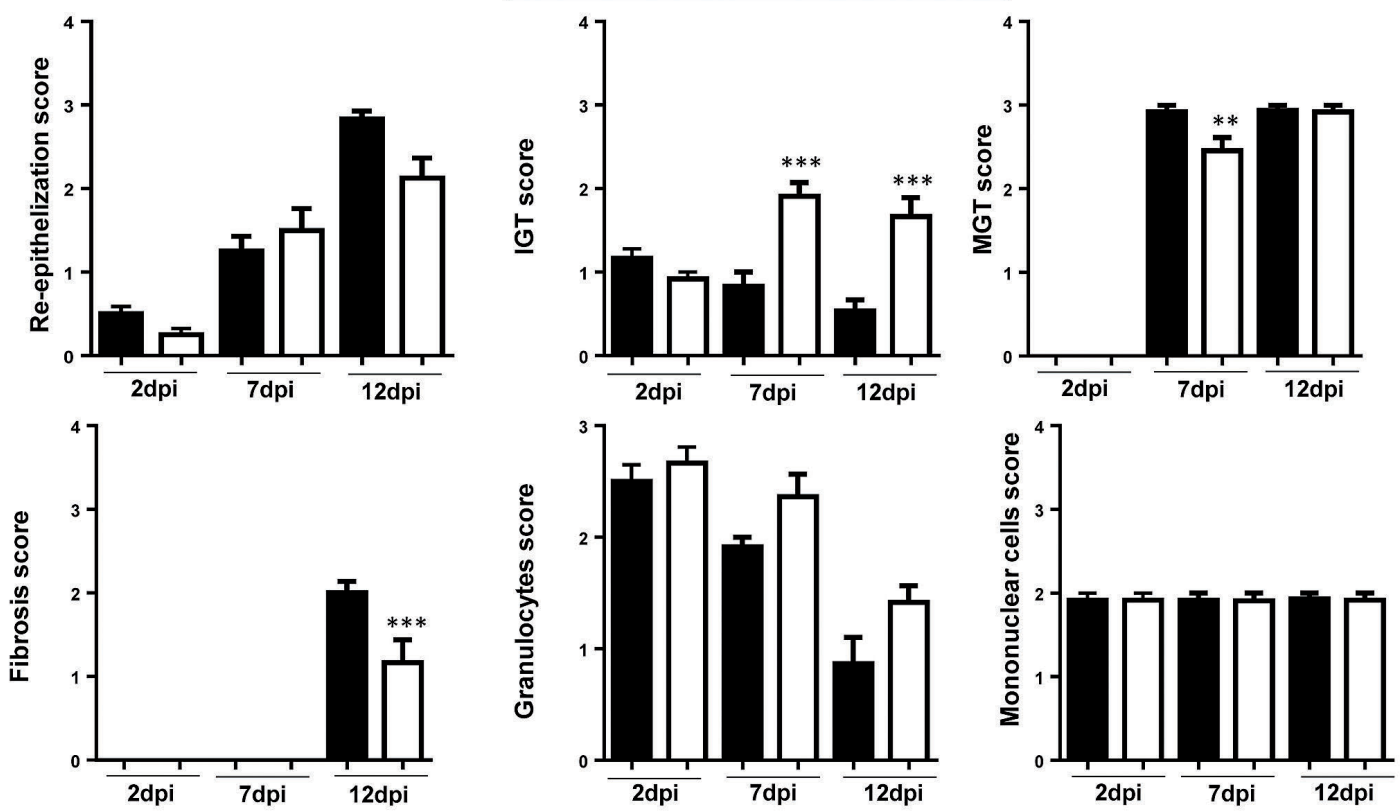

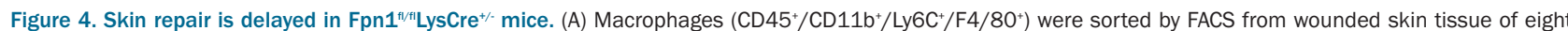
animals/group from Fpn1 $1^{\mathrm{t} / \mathrm{f}} \mathrm{LysCre} /$ and $\mathrm{Fpn}^{\mathrm{fl} / \mathrm{fl}} \mathrm{LysCre} \mathrm{Cr}^{+/}$mice at 2, 7 and 12 days post-injury (dpi). Ferroportin (FPN), transferrin receptor 1 (TfR1) and $\mathrm{H}$-ferritin (FtH) mRNA expression was assessed by quantitative real time polymerase chain reaction and normalized to the housekeeping gene 18S RNA. Data are presented as mean $\pm \mathrm{SEM} ; * P<0.01, * * P<0.001, * * * P<0.0001$. (B) Representative histology of Perls' Prussian blue iron staining of dorsal skin samples at 12 dpi in $\mathrm{Fpn}^{\mathrm{tt} / \mathrm{f}} \mathrm{LysCre}^{\%}$ and $\mathrm{Fpn}^{1 \mathrm{t} / \mathrm{f}} \mathrm{LysCre}{ }^{+/}$mice. Magnification 40X. A semi-quantitative evaluation of Perls' iron staining is shown on the right; $\mathrm{n}=6$ for each group; $\star * * P<0.0001$. (C) Kinetic analysis of skin excisional wound areas. Values represent mean \pm SEM of 24 values for each group; $* P<0.01$, $* \star P<0.001$ versus $\mathrm{Fpn}^{\mathrm{t} / \mathrm{f} / \mathrm{LysCre} \%}$. One representative experiment (6 mice/group) out of four is shown. The inset shows representative macroscopic images of Fpn $1^{\mathrm{fl} / \mathrm{f}} \mathrm{LysCre} /$ and $\mathrm{Fpn}^{\mathrm{t} / \mathrm{t} / \mathrm{LysCre}+/ /}$ mice skin wounds at $7 \mathrm{dpi}$. (D) Histological grading of wounds, based on separate evaluation of distinct features of the wound healing process, at 2 , 7 and 12 dpi. IGT: immature granulation tissue, MGT: mature granulation tissue. The semiquantitative score was defined as described in Online Supplementary Table $\mathrm{S} 2 ; \mathrm{n}=12$ for each group; $* * * P<0.0001, * * P<0.001$ versus Fpn1fl/flLysCre-/-. 

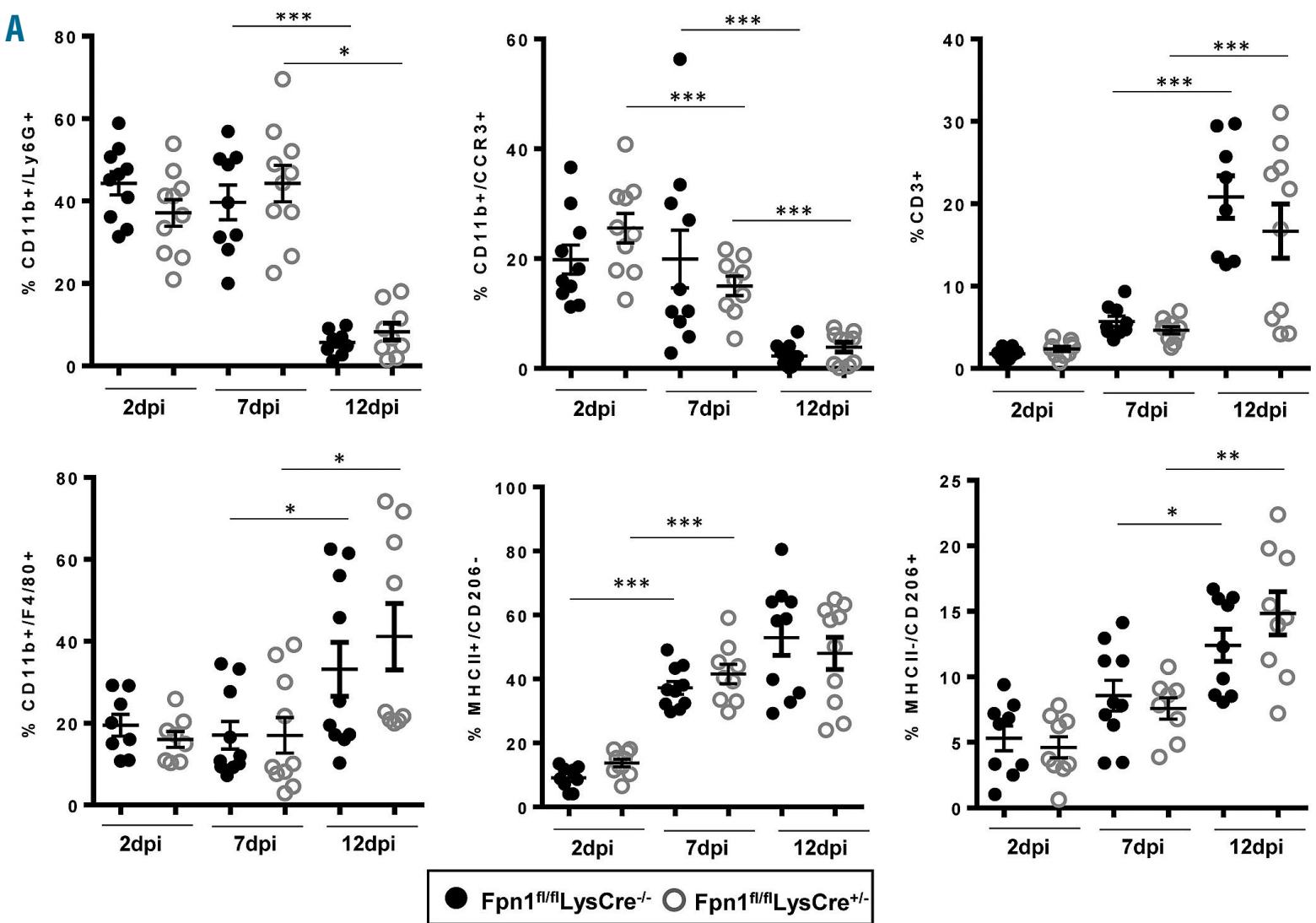

B

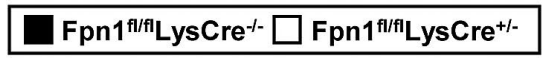
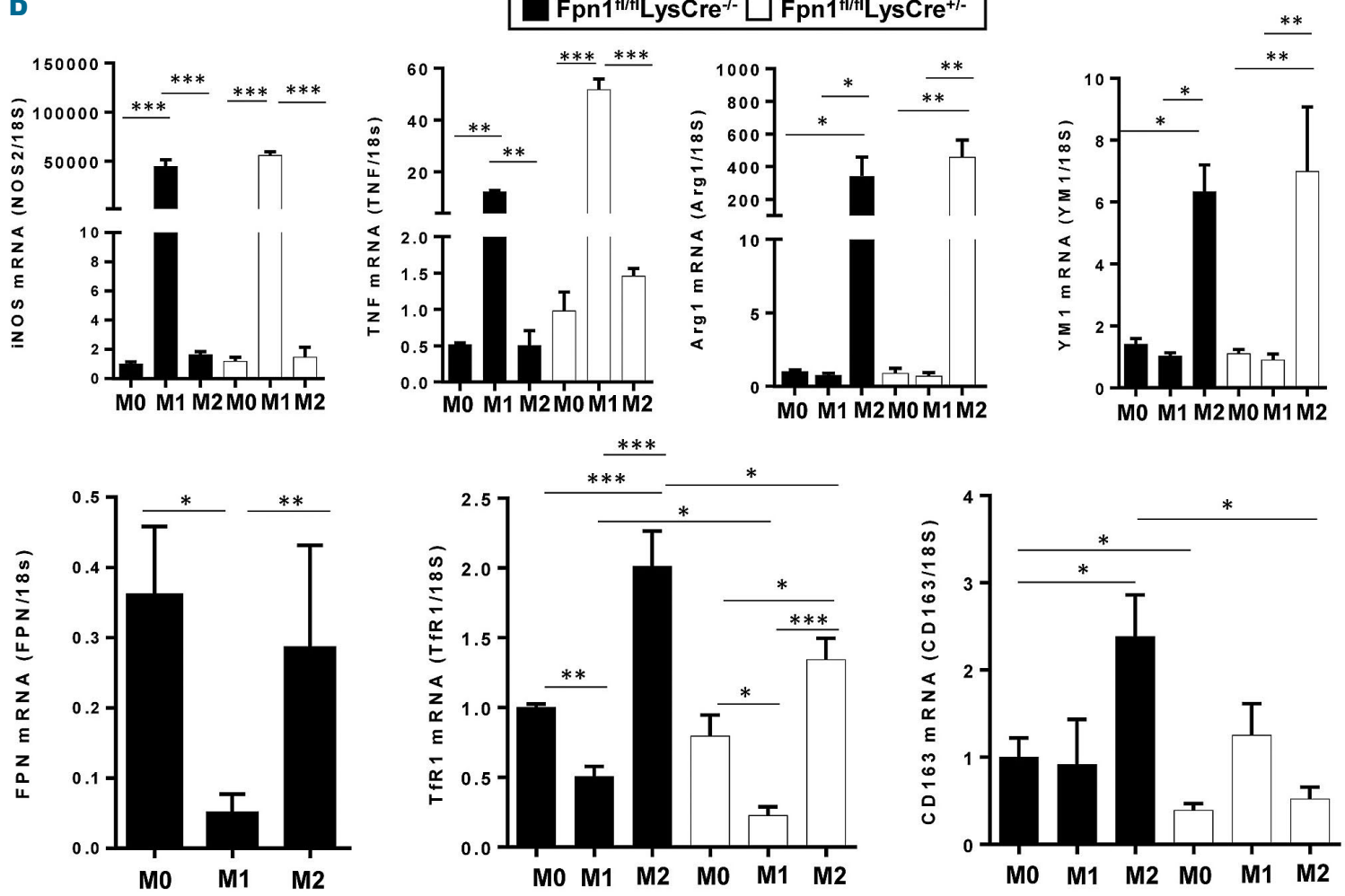

Figure 5. Wound-infiltrating leukocytes and macrophage polarization are not altered in Fpn1 $1^{\mathrm{t} / \mathrm{f}} \mathrm{LysCre}{ }^{+/}$mice. (A) Frequencies of neutrophils $\left(\mathrm{CD} 11 \mathrm{~b}^{+} / \mathrm{Ly}^{\mathrm{f}} \mathrm{G} \mathrm{G}^{+}\right)$,

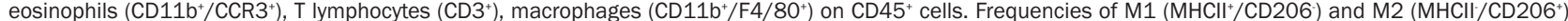
polarized macrophages on total live macrophages. Dots and black lines represent single animals and the mean $\pm \mathrm{SEM}$, respectively; $\mathrm{n}=10$ mice for each group;

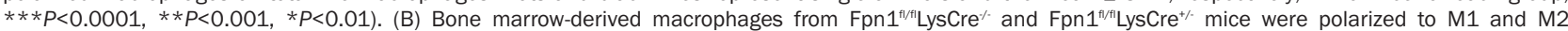
macrophages and relative iNOS, TNF $\alpha$, Arg1, YM1, FPN, TfR1 and CD163 mRNA levels were measured by quantitative real-time polymerase chain reaction at 24 h; results were normalized to the housekeeping gene 18S RNA (mean \pm SEM of 12 mice for each group; $* * * P<0.0001, * * P<0.001, * P<0.01$ ). 
wound lysates, but did not detect significant differences between the two mouse lines at any time-point (Online Supplementary Figure S5). Since iron accumulation in macrophages of Fpn1 $1^{\text {E// }} \mathrm{LysCre}^{+/}$mice could affect the polarization of these cells during the healing process,${ }^{15} \mathrm{we}$ investigated the distribution of the different polarized macrophages. As expected, an increase in
MHCII ${ }^{+}$CD206 M1 macrophages was detected already in the middle-proliferative phase, while a significant increase in $\mathrm{MHCII} / \mathrm{CD} 206^{+} \mathrm{M} 2$ macrophages was evident only in the late-remodeling phase, but no difference was found between Fpn1 $1^{\sharp / / 1} \mathrm{LysCre}^{+/-}$mice and their control littermates (Figure 5A). Moreover, we evaluated the expression of polarization markers in bone marrow-

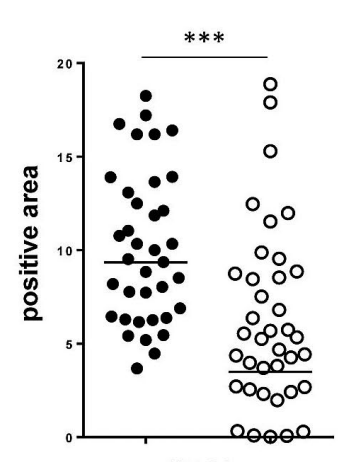

CD31
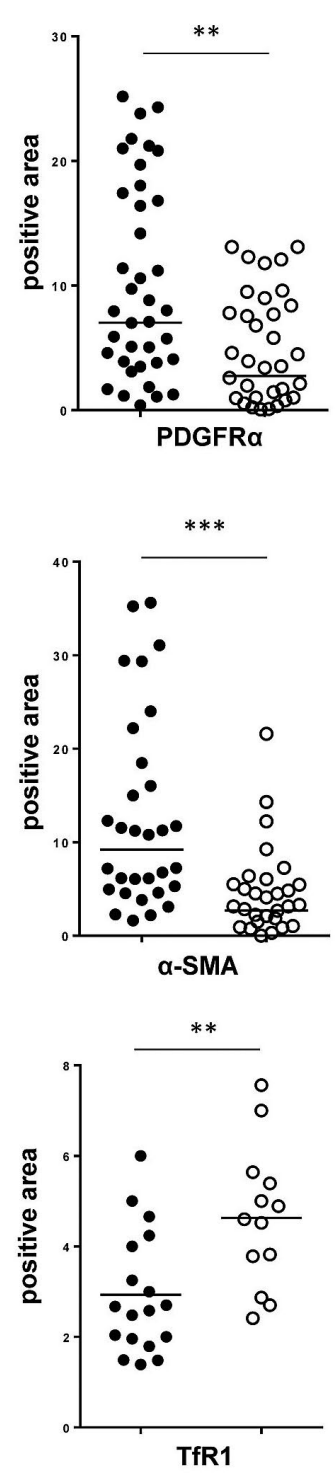

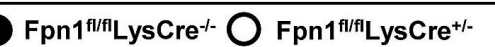
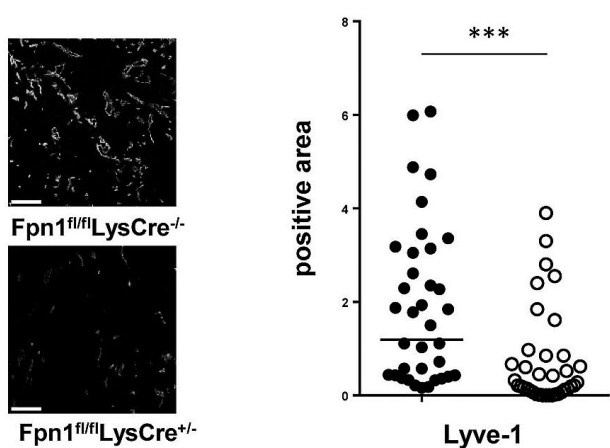

Lyve-1

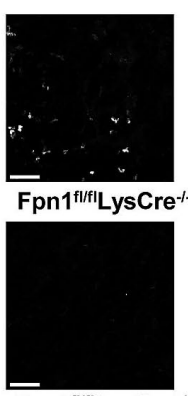

Fpn 1"1/fiLysCre+
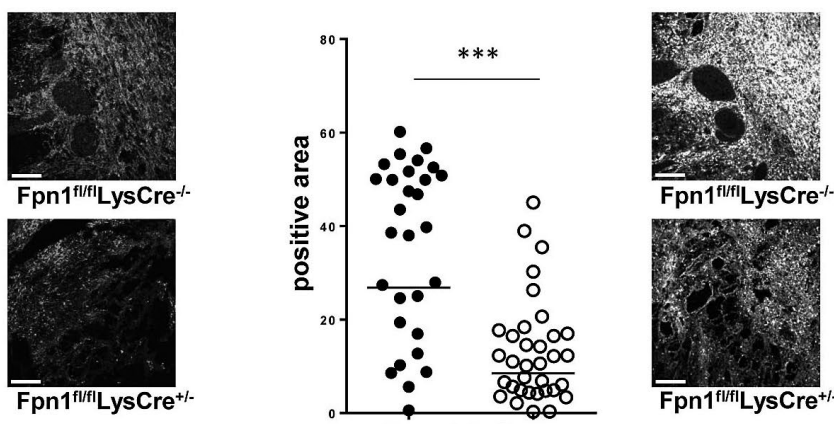

Type I Collagen
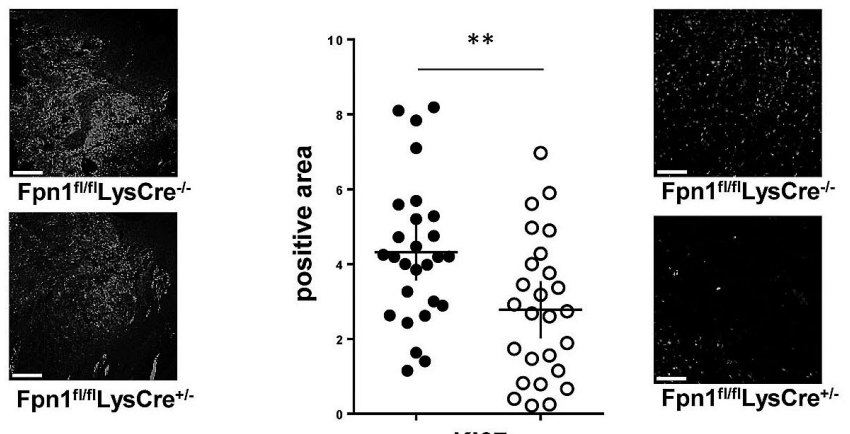

Ki67

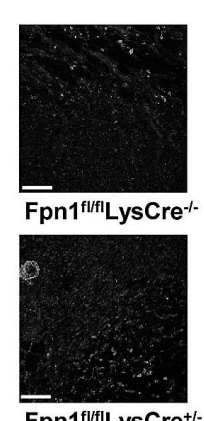

$\mathrm{Fpn}^{\text {fl/fil LysCre }}{ }^{+/-}$
Figure 6. Vessel and stromal cell reduction accompanied by iron deficiency and

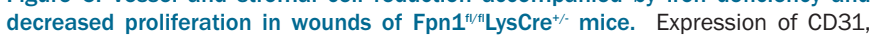
Lyve-1, collagen-1, PDFGR, $\alpha$ SMA, Ki67 and TfR1 after skin wounding at 7 dpi was assessed by confocal microscopy and the positive area expressed as \%. Each circle represents an analysis from a single confocal image (5-9 fields of vision/mouse, 6 mice/group), $* * * P<0.0001, * * P<0.001$. Representative confocal microscopy images are shown. Bars: $100 \mu \mathrm{m}$. Magnification: 40X. 
derived macrophages exposed in vitro to polarization stimuli, but again no difference was observed in markers for both M1 (iNOS and TNFa) and M2 (Arg1 and YM1) macrophages (Figure $5 \mathrm{~B}$ ). The expression of iron-related genes in bone marrow-derived macrophages of

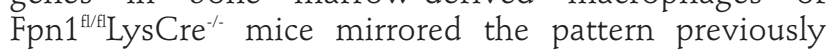
observed in human polarized macrophages,${ }^{15}$ with elevated expression of FPN, TfR1 and the hemoglobin/haptoglobin complex receptor CD163 in M2 macrophages. This finding is in line with the prominent expression of FPN in macrophages during the late phase of repair, when the M2 cell infiltrate is increased (Figures $4 \mathrm{~A}$ and $5 \mathrm{~A}$ ). Deletion of macrophage FPN resulted in lower expression of TfR1 and CD163 transcript levels in M2 macrophages (Figure 5B), possibly as a consequence of iron accumulation.

\section{Ferroportin deletion in macrophages affects stromal cells during wound healing}

Since FPN deletion in macrophages significantly affected the wound healing process but iron accumulation in FPN-deficient macrophages did not alter the inflammatory processes associated with wound healing, we evaluated whether the defective iron release by FPN-deficient macrophages affected the biology of surrounding stromal cells in the wound tissue. Confocal analysis at $7 \mathrm{dpi}$ showed reduced expression in Fpn $1^{\mathrm{E} / \mathrm{L}} \mathrm{LysCre}^{+/-}$mice, as compared to control littermates, of blood (CD31) and lymph vessel (Lyve-1) endothelium markers (Figure 6). This was accompanied by decreased expression of platelet-derived growth factor receptor- $\alpha$, a marker of mesenchymal cells, and lower levels of collagen I and alpha smooth muscle actin ( $\alpha S M A)$, which are markers of activated fibroblasts and myofibroblasts, respectively (Figure 6). Moreover, in the absence of macrophage FPN, surrounding stromal cells were iron-deficient, as indicated by upregulation of TfR1 expression, and proliferated less than control counterparts, as shown by decreased Ki67 expression (Figure 6). Taken together, these results indicate that the iron retention in macrophages caused by FPN deletion impairs blood vessel formation and stromal cell proliferation, leading to delayed skin repair.

\section{Discussion}

The role of erythrophagocytic macrophages as a source of iron for erythropoiesis is well established. ${ }^{16}$ However, macrophages may also be involved in iron redistribution at a local tissue level, thus affecting neighboring cells. We previously showed that FPN-mediated iron release from human macrophages supports in vitro cell proliferation. ${ }^{15}$ In the present study, we showed that a steady supply of iron released by macrophage FPN is essential for tissue homeostasis in two conditions, follicular development and wound healing, which share many similarities, including fast cell growth rate. ${ }^{6}$ Our study, therefore, underlines a new iron-related function of macrophages in tissue homeostasis and regeneration, in line with the increasing recognition of these cells' considerable functional polyvalence and trophic role, in addition to established immunological functions. ${ }^{30}$ We did not address the effect of FPN gene deletion in other myeloid cells affected in the LysM conditional model here adopted as their contribution to iron storage and release is negligible com- pared to that of macrophages. ${ }^{11,13}$

Our findings showing impaired hair follicle growth in mice with FPN deficiency in macrophages are in line with the report of similar hair and skin lesions in mice with altered expression of other proteins of iron metabolism, ${ }^{31}$. ${ }^{33}$ although in these other settings the presence of systemic iron deficiency/anemia did not allow the relative contributions of circulating iron versus local availability of macrophage-derived iron to be distinguished. We showed that the alopecia in mice with loss of macrophage FPN was not related to limited systemic iron availability, as evidenced by the lack of differences in serum iron availability and the similar hepatic and local hepcidin expression (Figure 1). Evidence that local iron release from macrophages, which are abundant in skin tissue (Figure 3), is more important than systemic iron levels was also provided by the persistence of alopecia after the return of normal hemoglobin and body iron levels (Figures 1 and 2), and by the absence of hair loss in hypoferremic and anemic Fpn $1^{\mathrm{E} / \mathrm{I}}$ LysCre ${ }^{-/}$mice (Figure 2), even when fed an iron-deficient diet for a long time. In line with the alopecia and delayed entry of the hair follicle into anagen exhibited by mice overexpressing $\mathrm{H}$ ferritin, ${ }^{34}$ we provide evidence that iron release from macrophages is required to sustain the rapid multiplication of hair follicle cells (Figure 3). In the absence of macrophage FPN, follicle epithelial cells are iron-deficient, as demonstrated by the increased expression of TfR1, and have a lower replication rate, as indicated by reduced Ki67 levels. The discrepancy with the lack of alopecia in a similar model of macrophage-specific FPN inactivation reported by Zhang and colleagues ${ }^{26}$ could be explained by the different iron content of the standard diet used (157 ppm versus 232, respectively) and by the different genetic backgrounds of the mice. Indeed, the role of dietary iron absorption, which is more important in mice than in humans, ${ }^{35}$ in correcting the alopecia was also indicated by the effect of switching to chow diet at weaning. Alopecia may result from insufficient iron availability caused by decreased local iron release (this study), Matriptase-dependent severe systemic iron deficiency ${ }^{32,33}$ (although the role of local FPN was not addressed in those studies) and iron sequestration in ferritin. ${ }^{34}$ The absence of alopecia in Fpn $1^{1 / / 1 / I}$ LysCre ${ }^{-/}$mice kept on an iron-deficient diet for almost 3 months suggests that local iron release may provide iron more directly in a paracrine fashion when circulating iron levels fall. We conclude that the essential role of macrophages in hair follicle cycling ${ }^{5}$ is not only related to their production of growth stimulators, such as Wnt, ${ }^{7}$ but also to the ability to supply the growing tissue with iron. Macrophages are part of the nurturing niche of stem cells in various tissues, ${ }^{36}$ including tumors. The results reported here in skin hair follicles raise the possibility that macrophage-dependent iron provision has a more general role in different stem cell niches.

We also report here a similar role for macrophagederived iron during skin wound healing, a complex tissue repair process consisting of overlapping phases of inflammation and tissue remodeling in which macrophages play a key role. ${ }^{2}$ The use of mice lacking FPN selectively in cells of the myeloid lineage allowed us to define the role of macrophage iron in wound healing in the absence of the systemic iron overload and large local iron accumulation present in other models. ${ }^{17,28}$ In the present setting, the disruption of iron export from local macrophages delayed wound healing, apparently by preventing neighboring 
mesenchymal and stromal cells from receiving the iron supply necessary for growth/differentiation. In line with the higher FPN expression in M2 than in M1 macrophages, ${ }^{15,37}$ the lack of macrophage FPN exerts its major effects in the middle-late phase of repair when the $M 1$ to M2 switch occurs. Indeed, in the late stages, normal M2 skin macrophages export iron through enhanced FPN expression, whereas FPN-deficient macrophages accumulate iron with concomitant induction of ferritin and repression of TfR1 (Figure 4A). The lower fibrosis score (Figure 4D) and the decreased expression of collagen-1 and $\alpha \mathrm{SMA}$ (Figure 6) show that the stromal component is compromised, as the absence of macrophage FPN resulted in iron deprivation and impaired proliferation of stromal cells (Figure 6). In this context, fibroblasts may not receive enough iron, which can be among the paracrine factors secreted by M2 macrophages to favor cell multiplication. ${ }^{38}$ A detrimental effect on collagen synthesis and assembly, which require iron-dependent prolyl hydroxylases, ${ }^{21}$ or other iron-dependent functions such as dihydroxy-docosahexaenoic acid production, ${ }^{39}$ may contribute to defective repair.

Our results also show that macrophage iron is essential for the development of the vascular network during tissue healing, as both lymphatic and blood vessels were reduced (Figure 6). Although the decrease of vascular structure caused by macrophage depletion was previously ascribed to the reduced production of vascular endothelial growth factor and transforming growth factor- $\beta,{ }^{9}$ the latter being also involved in extracellular matrix deposition and $\alpha \mathrm{SMA}$ expression, ${ }^{40}$ in our experimental model the levels of these growth factors were unchanged (Online Supplementary Figure S5). Similarly, given that hemoglobin levels of adult Fpn1 $1^{\mathrm{E} / \mathrm{L}} \mathrm{LysCre}^{+/}$mice were normal, defective oxygenation as a possible factor involved in impaired vascularization can be ruled out. Therefore, our results showing reduced neovessel density, reduced granulation tissue formation and decreased fibrosis in the absence of macrophage iron release, in the face of unchanged levels of prominent angiogenic and fibrogenic factors, such as vascular endothelial growth factor and transforming growth factor- $\beta$, support the relevance of the trophic role of macrophage-derived iron in the wound milieu.

Understanding the role of iron in macrophage production of inflammatory molecules has been hampered by contradictory findings. An increased inflammatory response was found in iron-depleted macrophages, ${ }^{41}$ but not in equally iron-deficient macrophages from $\mathrm{HFE}^{-1}$ mice, ${ }^{42}$ and other studies showed that iron levels correlate positively with the synthesis of pro-inflammatory cytokines. ${ }^{26,43}$ In addition, a pro-inflammatory state has been shown in macrophages and macrophage/microglia cells exposed to heme or iron ${ }^{28,29}$ and in hemorrhagic areas within tumors. ${ }^{44}$ Similarly, decreased iron release from macrophages, associated with pro-inflammatory activation and defective M2 polarization, impaired wound healing in chronic venous leg ulcers. ${ }^{17}$ Conversely, we found that iron retention in macrophages has no impact on leukocyte recruitment and activation as well as macrophage polarization (Figure 5 and Online Supplementary Figure S5). Moreover, in vitro polarized bone marrow-derived macrophages from the two mouse lines did not show differential expression of $\mathrm{M} 1$ and M2 markers (Figure 5B). Therefore, in our model, iron accumulation does not exacerbate the pro-inflammatory phenotype of wound healing-associated macrophages, in keeping with a recent study showing that iron did not increase M1 polarization of RAW264.7 macrophages. ${ }^{45}$ The conflicting results may be related to the different experimental models, the heterogeneity of macrophages and the exposure to different iron sources, such as heme iron which is highly toxic. ${ }^{46}$ In the absence of FPN, macrophages from Fpn $1^{\mathrm{f} / \mathrm{l}} \mathrm{LysCre}^{+/-}$mice accumulate iron in ferritin, which increases less than 2-fold (Figure 4A), but iron deposition seems less massive than in conditions such as chronic ulcers, ${ }^{17}$ in which iron content may increase 20 -fold, ${ }^{47}$ or hemolysis. ${ }^{29,44}$ In our experimental setting iron accumulation may, therefore, be insufficient to interfere with the M1/M2 switch and favor a proinflammatory state. A recent study demonstrated that FPN downregulation in macrophages impaired skeletal muscle regeneration after injury, ${ }^{48}$ but the effect of increased iron accumulation on the inflammatory profile of macrophages was not addressed.

In conclusion, the results of our study indicate that local macrophage FPN, by supplying iron to cells in the microenvironment, affects both the physiological context of follicular anagen and the pathophysiological context of wound healing. In its absence, stromal cells are iron-deficient and their proliferation is impaired (Figures 3 and 6). The importance of local iron recycling is underlined by the lack of changes in hepatic and skin hepcidin. A similar requirement for iron provided locally by macrophages has been described for the repair of skeletal muscle cells, in which iron retention in macrophages, by impairing myoblast proliferation, results in smaller myofibers. ${ }^{48}$ Iron should, therefore, be added to the list of trophic mediators produced locally by macrophages that stimulate the growth, differentiation and activity of neighboring parenchymal and stromal cells in order to maintain tissue homeostasis or repair.

\section{Acknowledgments}

This work was supported by grants from the Italian Association for Cancer Research (AIRC-IG 2016 \#19213 to ML) and MIUR (COFIN to GC). The authors would like to thank Nancy Andrews for providing Fpn $n^{\text {tith }}$ mice, Alberto Mantovani for support and helpful comments, and Eugenio Scanziani and Camilla Recordati for their help with the histological analysis.

\section{References}

1. Brancato SK, Albina JE. Wound macrophages as key regulators of repair: origin, phenotype, and function. Am J Pathol. 2011;178(1):19-25.

2. Wynn TA, Vannella KM. Macrophages in tissue repair, regeneration, and fibrosis.
Immunity. 2016:44(3):450-462.

3. Mantovani A, Biswas SK, Galdiero MR, Sica A, Locati M. Macrophage plasticity and polarization in tissue repair and remodelling. J Pathol. 2013;229(2):176-185.

4. Biswas SK, Mantovani A. Orchestration of metabolism by macrophages. Cell Metab. 2012;15(4):432-437

5. Stenn KS, Paus R. Controls of hair follicle cycling. Physiol Rev. 2001;81(1):449-494.

6. Ansell DM, Kloepper JE, Thomason HA, Paus R, Hardman MJ. Exploring the "hair growth-wound healing connection": anagen phase promotes wound re-epithelialization. J Invest Dermatol. 2011;131(2):518-528.

7. Castellana D, Paus $R$, Perez-Moreno $M$ Macrophages contribute to the cyclic activation of adult hair follicle stem cells. PLoS 
Biol. 2014·12(12):e1002002.

8. Mirza R, DiPietro LA, Koh TJ. Selective and specific macrophage ablation is detrimental to wound healing in mice. Am I Pathol. 2009;175(6):2454-2462

9. Lucas T, Waisman A, Ranjan R, et al. Differential roles of macrophages in diverse phases of skin repair. J Immunol. 2010;184(7):3964-3977.

10. Recalcati S, Locati M, Cairo G. Systemic and cellular consequences of macrophage control of iron metabolism. Semin Immunol. 2012;24(6):393-398.

11. Cairo G, Recalcati S, Mantovani A, Locati M. Iron trafficking and metabolism in macrophages: contribution to the polarized phenotype. Trends Immunol. 2011;32(6): 241-247.

12. Soares MP, Hamza I. Macrophages and iron metabolism. Immunity. 2016;44(3):492-504.

13. Ganz T, Nemeth E. Iron homeostasis in host defence and inflammation. Nat Rev Immunol. 2015;15(8):500-510.

14. Martinez FO, Gordon S, Locati M, Mantovani A. Transcriptional profiling of the human monocyte-to-macrophage differentiation and polarization: new molecules and patterns of gene expression. J Immunol. 2006;177(10):7303-7311.

15. Recalcati S, Locati M, Marini A, et al. Differential regulation of iron homeostasis during human macrophage polarized activation. Eur J Immunol. 2010;40(3):824-835.

16. Drakesmith $\mathrm{H}$, Nemeth $\mathrm{E}$, Ganz T. Ironing out ferroportin. Cell Metab. 2015;22(5):777787.

17. Sindrilaru A, Peters T, Wieschalka S, et al. An unrestrained proinflammatory M1 macrophage population induced by iron impairs wound healing in humans and mice. J Clin Invest. 2011;121(3):985-997.

18. Lundvig DM, Immenschuh S, Wagener FA. Heme oxygenase, inflammation, and fibrosis: the good, the bad, and the ugly? Front Pharmacol. 2012;3:81.

19. Cairo G, Bernuzzi F, Recalcati S. A precious metal: Iron, an essential nutrient for all cells. Genes Nutr. 2006;1(1):25-39.

20. Muckenthaler MU, Rivella S, Hentze MW, Galy B. A red carpet for iron metabolism. Cell. 2017;168(3):344-361.

21. Markolovic S, Wilkins SE, Schofield CJ. Protein hydroxylation catalyzed by 2-oxoglutarate-dependent oxygenases. J Biol Chem. 2015;290(34):20712-20722.

22. Singer AJ, Clark RA. Cutaneous wound healing. N Engl J Med. 1999;341(10):738-746.

23. Gurtner GC, Werner S, Barrandon Y,
Longaker MT. Wound repair and regeneration. Nature. 2008;453(7193):314-321

24. Donovan A, Lima CA, Pinkus JL, et al. The iron exporter ferroportin/Slc40a1 is essential for iron homeostasis. Cell Metab. 2005;1(3):191-200.

25. Clausen BE, Burkhardt C, Reith W, Renkawitz R, Förster I. Conditional gene targeting in macrophages and granulocytes using LysMcre mice. Transgenic Res. 1999;8(4):265-277.

26. Zhang Z, Zhang F, An P, et al. Ferroportin1 deficiency in mouse macrophages impairs iron homeostasis and inflammatory responses. Blood. 2011;118(7):1912-1922.

27. Kautz L, Jung G, Valore EV, Rivella S, Nemeth E, Ganz T. Identification of erythroferrone as an erythroid regulator of iron metabolism. Nat Genet. 2014;46(7):678-684

28. Kroner A, Greenhalgh AD, Zarruk JG, Passos Dos Santos R, Gaestel M, David S. TNF and increased intracellular iron alte macrophage polarization to a detrimental M1 phenotype in the injured spinal cord. Neuron. 2014;83(5):1098-1116.

29. Vinchi F, Costa da Silva M, Ingoglia G, et al Hemopexin therapy reverts heme-induced proinflammatory phenotypic switching of macrophages in a mouse model of sickle cell disease. Blood. 2016;127(4):473-486.

30. Wynn TA Chawla A, Pollard JW. Macrophage biology in development, homeostasis and disease. Nature. 2013;496(7446):445-455.

31. Nicolas G, Bennoun M, Porteu A, et al. Severe iron deficiency anemia in transgenic mice expressing liver hepcidin. Proc Natl Acad Sci USA. 2002;99(7):4596-4601

32. Du X, She E, Gelbart T, et al. The serine protease TMPRSS6 is required to sense iron deficiency. Science. 2008;320(5879):1088-1092.

33. Folgueras AR, de Lara FM, Pendas AM, et al. Membrane-bound serine protease matriptase-2 (Tmprss6) is an essential regulator of iron homeostasis. Blood. 2008;112(6):25392545 .

34. Hasegawa S, Harada K, Morokoshi Y, Tsukamoto S, Furukawa T, Saga T. Growth retardation and hair loss in transgenic mice overexpressing human $\mathrm{H}$-ferritin gene. Transgenic Res. 2013;22(3):651-658.

35. Ganz T. Systemic iron homeostasis. Physiol Rev. 2013;93(4):1721-1741

36. Kaur S, Raggatt LJ, Batoon L, Hume DA, Levesque JP, Pettit AR. Role of bone marrow macrophages in controlling homeostasis and repair in bone and bone marrow niches. Semin Cell Dev Biol. 2017;61:12-21.
37. Corna G, Campana L, Pignatti E, et al. Polarization dictates iron handling by inflammatory and alternatively activated macrophages. Haematologica. 2010;95(11): 1814-1822.

38. Ploeger DT, Hosper NA, Schipper M, Koerts JA, de Rond S, Bank RA. Cell plasticity in wound healing: paracrine factors of M1/ M2 polarized macrophages influence the phenotypical state of dermal fibroblasts. Cell Commun Signal. 2013;11(1):29

39. Lu Y, Tian H, Hong S. Novel 14,21-dihydroxy-docosahexaenoic acids: structures, formation pathways, and enhancement of wound healing. J Lipid Res. 2010;51(5):923392.

40. Hinz B. Formation and function of the myofibroblast during tissue repair. J Invest Dermatol. 2007;127(3):526-537.

41. Pagani A, Nai A, Corna G, et al. Low hepcidin accounts for the proinflammatory status associated with iron deficiency. Blood. 2011;118(3):736-746.

42. Roy CN, Custodio AO, de Graaf J, et al. An Hfe-dependent pathway mediates hyposideremia in response to lipopolysaccharide-induced inflammation in mice. Nat Genet. 2004:36(5):481-485.

43. Wang L, Johnson EE, Shi HN, Walker WA, Wessling-Resnick M, Cherayil BJ Attenuated inflammatory responses in hemochromatosis reveal a role for iron in the regulation of macrophage cytokine translation. J Immunol. 2008;181(4):27232731

44. Costa da Silva M, Breckwoldt MO, Vinchi F, et al. Iron induces anti-tumor activity in tumor-associated macrophages. Front Immunol. 2017;8:1479.

45. Gan ZS, Wang QO, Li JH, Wang XL, Wang YZ, Du HH. Iron reduces M1 macrophage polarization in RAW264.7 macrophages associated with inhibition of STAT1. Mediators Inflamm. 2017;2017:8570818.

46. Gozzelino R, Jeney V, Soares MP Mechanisms of cell protection by heme oxygenase-1. Annu Rev Pharmacol Toxicol. 2010;50:323-354.

47. Ackerman Z, Seidenbaum M, Loewenthal E, Rubinow A. Overload of iron in the skin of patients with varicose ulcers. Possible contributing role of iron accumulation in progression of the disease. Arch Dermatol. 1988;124(9):1376-1378.

48. Corna G, Caserta I, Monno A, et al. The repair of skeletal muscle requires iron recycling through macrophage ferroportin. J Immunol. 2016;197(5):1914-1925. 